\title{
Effect of Porcine Small Intestinal Submucosa on Acute Full-Thickness Wounds in Dogs
}

\author{
SANDRA P. SCHALLBERGER, Dr. Med Vet, FVH, BRYDEN J. STANLEY, BVMS, MVetSc, Diplomate ACVs, \\ JOE G. HAUPTMAN, DVM, MS, Diplomate ACVs, and BARBARA A. STEFICEK, DVM, PhD, Diplomate ACVP
}

\begin{abstract}
Objective-To evaluate the effects of porcine small intestinal submucosa (PSIS) on the healing of full-thickness wounds in dogs, specifically the appearance of granulation tissue, percent epithelialization and contraction, histologic variables of inflammation and repair, and aerobic culture results.

Study Design-Prospective, controlled, experimental study.

Animals-Purpose-bred, female dogs $(\mathrm{n}=10)$.

Methods-Wounds were created bilaterally on the trunk; 1 side as a control and 1 treated with PSIS. First appearance of granulation tissue was recorded. Total wound area, open wound area, and epithelialized area were measured at 21 time points-wound contraction and percent epithelialization were calculated. Aerobic cultures were taken at 4 time points and wound biopsies at 8. Histologic features were graded into an Acute Inflammation Score and Repair Score.

Results-There was no difference in first appearance of granulation tissue between PSIS-treated and control wounds. Wound contraction was significantly faster in control wounds as was percent epithelialization after day 21. Histologic Acute Inflammation Scores were significantly higher in PSIS-treated wounds compared with control wounds on days 2 and 6 . There were no differences in Histologic Repair Scores between PSIS-treated and control wounds or in aerobic culture results.

Conclusion-Wounds treated with PSIS contract more slowly, epithelialize less, and have more pronounced acute inflammation after implantation than control wounds.

Clinical Relevance-Acute, full-thickness wounds in dogs do not benefit from treatment with PSIS.

(C) Copyright 2008 by The American College of Veterinary Surgeons
\end{abstract}

\section{INTRODUCTION}

$\mathrm{E}$ XTENDED SKIN loss, whether secondary to trauma, congenital defects, infection, or neoplastic resections, can pose substantial challenges for surgical reconstruction. Many techniques have been developed to achieve tension-free wound closure, including a variety of local and distant mobilization and reconstructive procedures. Size and location of the defect and adjacent vital structures, however, may constrain these techniques. Auto-, allo-, or xenografts are alternate strategies for temporary or permanent closure of large skin defects, but these can be associated with important complications, such as donor site morbidity, infection, rejection, or transmission of infectious agents. ${ }^{1-4}$ Synthetic and biological wound dressings are currently used in clinical applications. Synthetic wound dressings have multiple advantages: ready availability at a reasonable cost, long-term storage, and provision of necessary characteristics like hydration and protection against mechanical and infectious agents. In large defects, however, they act as temporary wound coverage until definitive reconstruction is performed.

From the Department of Small Animal Clinical Sciences, College of Veterinary Medicine, Michigan State University, East Lansing, MI; and the Diagnostic Center for Population and Animal Health, College of Veterinary Medicine, Michigan State University, 4125 Beaumont Road, East Lansing, MI.

Presented at the ACVS Symposium: Chicago, October 18, 2007.

Address reprint requests to Bryden J. Stanley, BVMS, MVetSc, Diplomate ACVS, Department of Small Animal Clinical Sciences, College of Veterinary Medicine, Michigan State University, East Lansing, MI 48824. E-mail: stanle32@cvm.msu.edu.

Submitted November 2007; Accepted March 2008

(C) Copyright 2008 by The American College of Veterinary Surgeons

0161-3499/08

doi:10.1111/j.1532-950X.2008.00398.x 
Biological wound dressings aim to become incorporated in the wound bed, providing a scaffold that promotes adhesion and migration of fibroblasts and keratinocytes. In vitro and in vivo investigations have sought to develop an implantable wound dressing that can ideally integrate into the wound while optimizing dermal and epidermal restoration. ${ }^{5-9}$ Growth factors and cytokines retained in these dressings are also thought to enhance healing. ${ }^{10-12}$ In people, collagen-based dermal substitutes followed by an epidermal autograft, or more recently bioengineered bilayered skin substitutes ${ }^{13-16}$ provide the closest product to the ideal wound dressing. ${ }^{17-19}$

In veterinary medicine, biological wound dressings such as allogeneic peritoneum, ${ }^{20}$ amnion, ${ }^{21,22}$ omentum, ${ }^{23-25}$ collagen dressings, ${ }^{26,27}$ and more recently extracellular matrix (ECM) products ${ }^{20,28,29}$ have been used to treat open wounds in dogs and horses with mixed success.

Currently, there are 2 ECM products in the veterinary market: porcine urinary bladder submucosa (PUBS) and porcine small intestinal submucosa (PSIS). Both are decellularized matrices consisting of a complex array of collagens, proteoglycans, glycosaminoglycans, and glycoproteins. ${ }^{30,31}$ They are reported to contain active growth factors, such as FGF-2, TGF $\beta$, and VEGF, ${ }^{32,33}$ making these materials bioactive constructs that are able to promote tissue remodeling. Initial investigation also demonstrated a possible antibacterial effect of the PSIS. ${ }^{34}$

There are numerous, mostly experimental, reports on the application of ECM bioscaffolds in the repair and reconstitution of many soft tissue structures with variable success. Tissues include the lower urinary tract, ${ }^{35-37}$ laryngeal cartilage, ${ }^{38}$ esophagus, ${ }^{39}$ abdominal wall, ${ }^{40-45}$ diaphragm, ${ }^{46,47}$ dura mater, ${ }^{48}$ blood vessels, ${ }^{49-51}$ tendons, ${ }^{52-56}$ ligaments, ${ }^{57,58}$ fascia, ${ }^{59}$ menisci, ${ }^{60-63}$ and bone. ${ }^{64}$ Both commercially available ECM matrices on the veterinary market are promoted as implantable products to accelerate wound healing in dogs and cats. Numerous studies have shown beneficial results in people in the treatment of wounds using PSIS ${ }^{65-67}$; however, very few reports have thoroughly studied its application in clinical veterinary medicine. ${ }^{20,29,68}$

Our purpose was to compare the effect of PSIS with a standard wound management protocol for large fullthickness wounds in dogs. We speculated that PSIS would provide a 3-dimensional matrix for cell migration and angiogenesis, thus promoting fibroplasia, epithelialization, and contraction. We adopted the null hypothesis that there would be no difference in first appearance of granulation tissue, epithelialization, or contraction between the 2 treatments. Additionally, we evaluated the effects of PSIS on histologic indicators of acute inflammation and wound repair, and reported the results of aerobic culture.

\section{MATERIALS AND METHODS}

Adult purpose-bred female mongrel dogs $(\mathrm{n}=10)$ weighing between 10 and $20 \mathrm{~kg}$, aged 1-3 years were acquired. Physical examination, complete blood count, and serum biochemistry profile were performed on each dog before study entry.

\section{Study Design}

Two $4 \times 4 \mathrm{~cm}$, full-thickness skin defects were created bilaterally on the trunk resulting in 4 wounds/dog. On 1 side, a single layer of commercially available PSIS was placed in both cranial and caudal wounds according to manufacturer's instruction and served as the treatment group. Wounds on the contralateral side served as the control group. Cranial wounds on both sides were used for tissue biopsy and histopathologic evaluation whereas caudal wounds were used for wound planimetry and bacterial cultures.

Wounds were studied for 70 days. Bandage changes and planimetry were performed on days $0,2,4,6,9,12,15,18,21$, $24,28,31,35,38,42,45,48,52,55,62$, and 69 . Biopsies for histopathologic evaluation were taken on days $0,2,4,6,9,15$, 21 , and 31. Swabs for aerobic cultures were taken from the caudal wounds on days $0,2,4,9$, and 15 .

\section{Technique}

On day 0 , dogs were medicated with acepromazine maleate $(0.05 \mathrm{mg} / \mathrm{kg}$ intramuscularly [IM]) and butorphanol tartrate $(0.4 \mathrm{mg} / \mathrm{kg} \mathrm{IM})$. A cephalic intravenous (IV) catheter was placed and anesthesia was induced with thiopental $(10-15 \mathrm{mg} /$ $\mathrm{kg}$ IV to effect) and maintained isoflurane (baseline concentration, $2 \%$ delivered in oxygen $30 \mathrm{~mL} / \mathrm{kg} / \mathrm{h}$ ). Lactated Ringer's solution $(10 \mathrm{~mL} / \mathrm{kg} / \mathrm{h}$ IV) was administered during anesthesia. Dogs were positioned in sternal recumbency and the hair on the dorsum of the trunk from the neck to the gluteal region was clipped and the skin prepared for aseptic surgery.

Using strict aseptic technique, two $4 \times 4 \mathrm{~cm}$ full-thickness skin defects were created on each side of the trunk $5 \mathrm{~cm}$ ventral to dorsal midline, just caudal to the scapula. The distance between the cranial and the caudal wounds was $10 \mathrm{~cm}$ (Fig 1).

For all wounds, the cutaneous trunci muscle of the panniculus carnosus was excised. Wounds were blotted with sterile gauze until hemostasis was achieved. Treatment and control sides were randomly assigned by coin toss. A single sheet of sterile PSIS (VET BIOSIST ${ }^{\mathrm{TM}}$; Cook Biotech Inc., West Lafayette, IN) was applied to the wounds according to manufacturer's instruction. After trimming the sheet and letting it soak in sterile saline $(0.9 \% \mathrm{NaCl})$ solution for 2 minutes, it was placed into the cranial and caudal wounds on the assigned treatment side. Four simple interrupted sutures (4-0 polydioxanone) were placed in each corner of the wound to anchor the PSIS to the skin edges (Fig 2). Wounds on the contralateral (control) side had 4 interrupted simple interrupted sutures in each corner. Hydrogel dressings $\left(\right.$ Curagel $^{\mathrm{TM}}$; Tyco Healthcare Group/Kendall, Mansfield, MA) were applied postoperatively on all 4 wounds. This semiocclusive 


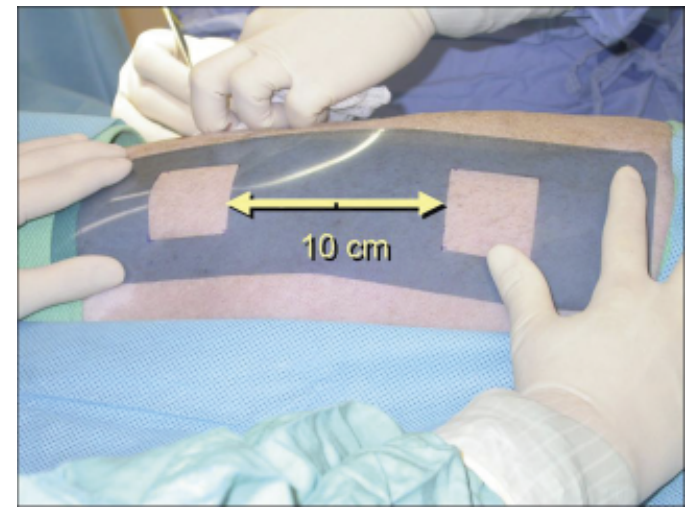

Fig 1. Left lateral view showing intraoperative placement of the template used to standardize wound size to $4 \times 4 \mathrm{~cm}$.

contact layer dressing was then secured with a dressing retention sheet (Hypafix ${ }^{\mathbb{B}}$; BSN medical GmbH \& Co. KG, Hamburg, Germany). Absorbent cotton cast padding (Specialist ${ }^{\mathbb{B}}$; BSN Medical Ltd., Brierfield, UK) was applied in multiple layers around the chest, criss-crossed in front of the forelimbs, and secured with an elastic bandage $\left(\operatorname{Vetrap}^{\mathrm{TM}}\right.$; 3M Animal Care Products, St. Paul, MN).

Butorphanol tartrate $(0.4 \mathrm{mg} / \mathrm{kg}$, IM, every 6 hours $)$ was administered after surgery for 24 hours. Carprofen $(4.4 \mathrm{mg} / \mathrm{kg}$ subcutaneously) was administered before recovery from anesthesia and continued orally for 7 days $(4.4 \mathrm{mg} / \mathrm{kg}$ orally every 24 hours).

Amoxicillin trihydrate and clavulanate potassium $(13.75 \mathrm{mg} /$ $\mathrm{kg}$ orally every 12 hours) were administered over 7 days

\section{Bandage Changes, Data Collection, and Evaluation}

Bandages were inspected daily for integrity and changed according to the schedule previously described. Bandage changes followed this protocol unless the bandage was stained

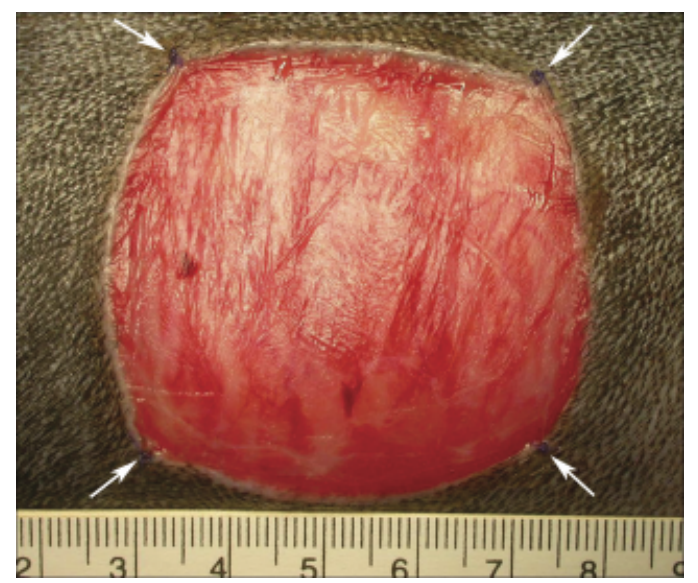

Fig 2. Postoperative view of a porcine small intestinal submucosa-treated wound. Note the placement of sutures in each corner (arrows), to secure the porcine small intestinal submucosa sheet in place. or was disheveled, which resulted in either reinforcement or replacement.

Dogs were sedated with acepromazine maleate $(0.05 \mathrm{mg} /$ $\mathrm{kg}, \mathrm{IV})$ and butorphanol tartrate $(0.4 \mathrm{mg} / \mathrm{kg}$, IV) on the days of bandage changes, and isoflurane ( $2-4 \%$ in oxygen) was administered by face mask when biopsies were taken. Bandage changes were performed using aseptic technique. Wounds were carefully cleansed with sterile saline. PSIS was evaluated for integrity and adherence and was replaced as necessary according to manufacturer's instruction, or fenestrated if fluid accumulation beneath the sheet was observed. First appearance of granulation tissue was documented. The hydrogel dressing was replaced on all the wounds at each bandage change. All data were obtained from the caudal wounds except the biopsies, which were taken from the cranial wounds to avoid distorting the wounds for planimetry.

\section{Planimetry}

Fine-resolution digital photographs $(1280 \times 960$ pixels $)$ of the caudal wounds were taken on day 0 and at each bandage change (total of 21 time points). A carefully positioned measurement scale was included in the picture, and uploaded into a wound tracing software program (WoundMatrix ${ }^{\mathrm{B}}$; GWR Medical Inc., Chadds Ford, PA). After calibration, each wound was measured and the areas of interest were defined; namely open wound area (i.e., pregranulation or granulation area) and epithelialization tissue; epithelialization being the area of new epithelium surrounding the open wound area, without the presence of hair follicles. Those areas were color coded and traced by 2 individuals (S.P.S., B.J.S.). Using the software application, the open wound area, the epithelialized area, and the total wound area (i.e., sum of the latter 2 areas) were calculated in $\mathrm{cm}^{2}$. From these results, the following measurements were calculated for each time point: (1) percent contraction with respect to the original wound size (\% contraction day $_{n}=100-\left(\left[\right.\right.$ total wound area day $_{n} /$ original wound area $\left.\left.\mathrm{day}_{0}\right] \times 100\right)$ and $(2)$ percent epithelialization of the total wound area $\left(\%\right.$ epithelialization $\mathrm{day}_{\mathrm{n}}=$ area of epithelium $\operatorname{day}_{\mathrm{n}} /$ total wound area day $_{\mathrm{n}} \times 100$ ).

\section{Histologic Evaluation}

Tissue biopsies for histologic evaluation were obtained from the cranial wounds using the following protocol. A disposable dermal biopsy punch (8-mm diameter) was used and locations of the biopsy sites within the wound were systematically rotated in a clockwise fashion in all wounds. Samples were fixed in $10 \%$ neutral-buffered formalin, and processed for light microscopy. Representative sections were stained with hematoxylin and eosin (H\&E) and microscopically evaluated by a board-certified veterinary pathologist (B.A.S.) who was unaware of sample grouping.

Criteria used for scoring of tissue alterations were defined before histologic evaluation of the sections. For the samples on days $0,2,4,6,9$, and 15 , the concentration of neutrophilic cellular infiltration and the degree of edema, hemorrhage, and necrosis were evaluated and scored: $0=$ none, $1=$ minimal, 
$2=$ moderate, $3=$ marked. The criteria used to define the concentration of cellular infiltrates were as follows: $0=$ within normal histologic limits, $1=$ scattered, $2=$ clustered or nodular, and 3 =diffuse. Histologic evaluation of tissue edema was based primarily on distribution within the sections, with $0=$ none, $1=$ focal, $2=$ localized (regional), and $3=$ diffuse. The degree or extent of hemorrhage within the tissue sections was subjectively and comparatively designated as $0=$ none, $1=$ mild, $2=$ moderate, and $3=$ severe. The necrosis component was evaluated utilizing the following histopathologic criteria: $0=$ none, $1=$ focal, $2=$ nodular $/$ regional, and $3=$ diffuse (tracking along fascial planes). These 4 histologic features were weighted equally and plotted at each time point to check for any graphical interaction of each composite by group, before being summed to formulate a Histologic Acute Inflammation Score (HAIS; range 0-12).

For days $0,2,4,6,9,15,21$, and 31 , the following variables were evaluated using the same scoring system $(0=$ none, $1=$ minimal, 2 = moderate, 3 = marked): fibroblast proliferation, collagen density, and neovascularization. Fibroblast proliferation was designated, histologically, by pattern and degree of tissue involvement. Scoring criteria were as follows: $0=$ none, $1=$ focal (loose), $2=$ locally extensive, and $3=$ effacing normal tissue architecture. Microscopic interpretation of collagen density was based on intensity and depth of distribution within tissue sections. Scoring values were defined as $0=$ none, $1=$ superficial dermal, $2=$ superficial to mid dermal, and $3=$ superficial dermal to subcutaneous. Similar to fibroblast proliferation, the neovascularization component was scored on histologic pattern and degree of tissue involvement: $0=$ none, $1=$ focal (loose), $2=$ transdermal, and $3=$ effacing normal tissue architecture. These 3 histologic features were weighted equally and plotted at each time point to check for any graphical interaction of each composite by group, before being summed to formulate a Histologic Repair Score (HRS; range 0-9).

To evaluate the histologic appearance of the PSIS material alone, samples of a rehydrated PSIS sheet were examined with an H\&E stain.

\section{Microbiology}

Aerobic bacterial cultures were taken from the caudal wounds on both sides on day 0 and postoperative days 4, 9, and 15 using a commercially available collection and transport system $\left(\mathrm{BBL}^{\mathrm{TM}}\right.$ Culture Swab ${ }^{\mathrm{TM}}$; Becton, Dickinson and Company, Sparks, MA). Culture media were Enriched Blood Agar, Columbia CNA 5\% blood agar with colistin and nalidixic acid, MacConkey agar and Thioglycollate broth. Samples were incubated and evaluated each day for quantity and species of bacteria. Isolated bacteria were identified and quantified by standard methods. Cultures were incubated for 4 days on the Enriched Blood Agar and Thioglycollate broth, and for 2 days on Columbia CNA and MacConkey agar before being considered negative.

\section{Statistical Analysis}

The response variables were total wound area $\left(\mathrm{cm}^{2}\right), \%$ contraction, $\%$ epithelialization, HAIS, and HRS. The factors that could affect the response variables were treatment (PSIS, control), time (21 timepoints for planimetery, 6 for HAIS and 8 for HRS) and dog (10). Post hoc tests of all times to time ${ }_{0}$ were by means of Bonferroni t-test. Post hoc across treatment comparisons at each time were by means of t-test. Data were analyzed by means of a 3-factor ANOVA with the fixed effects of treatment and time and the random effect of dog (SAS PROC MIXED, SAS Institute Inc., Cary, NC). The level of significance was set at $P<0.05$. The number of positive aerobic cultures was compared across treatment at each time by means of a minimum $\chi^{2}$.

\section{RESULTS}

Physical examination, complete blood count and serum biochemistry profile were within normal reference ranges for all dogs. Dogs tolerated surgery and the bandages well. Toward study end, when the wounds were almost completely healed, the dogs appeared mildly irritated with the bandages and occasionally managed to take them off overnight. Granulation tissue was grossly detected between days 4-9 in the PSIS-treated and control wounds.

Fluid accumulation beneath the PSIS sheet during the first couple of days was treated by fenestration of the sheet according to manufacturer's instructions, using a \#11 surgical blade. Hydration status of the wounds throughout the study was moist and healthy, except toward study end when some dogs were able to take off their bandages. In those dogs desiccation of the wound bed was noted.

\section{Planimetry}

Wound Size. There was an initial increase in wound size in PSIS-treated and control wounds during the first 6 days. Wound edges retracted resulting in wounds larger than the $4 \times 4 \mathrm{~cm}$, and the PSIS-treated wounds retracted significantly less than the control wounds. There was a significant difference in total wound area between the PSIStreated wounds and the control wounds almost through the entire study time. PSIS-treated wounds were significantly smaller on days $0,2,4,6$, and 9 , but significantly larger on days 18, 24, 28, 31, 38, 42, 45, and 52 (Fig 3).

Contraction. Percent contraction was significantly larger in the control wounds compared with PSIS-treated wounds at all data points between days 18 and 55 (Fig 4).

Epithelialization. Percent epithelialization of the wound was significantly greater in the control wounds compared with the PSIS-treated wounds at all data points after day 21 (Figs 5 and 6).

\section{Histopathology}

Morphologic findings of control and PSIS-treated wounds appeared, in general, to reflect the basic phases of 


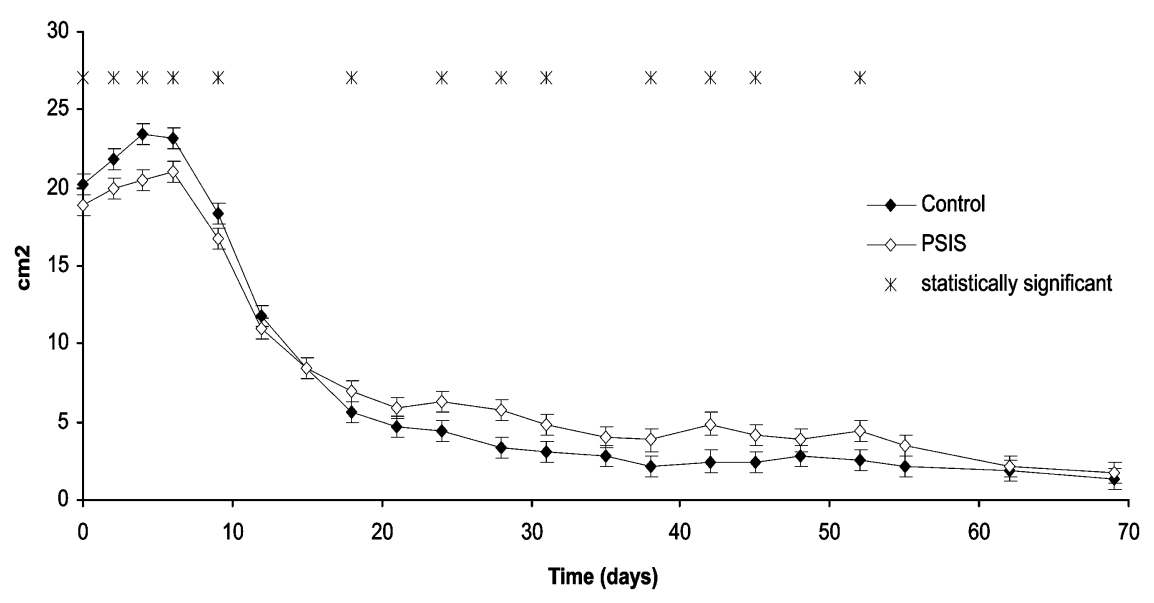

Fig 3. Total wound area $\left(\mathrm{cm}^{2}\right)$, representing the sum of open wound area and epithelialization. Note initial enlargement during the first 6 days in porcine small intestinal submucosa-treated wounds and the control wounds because of elastic recoil. Initially, the control wounds were significantly larger than the porcine small intestinal submucosa-treated wounds, but with contraction, the control wounds were significantly smaller for most of the time points. For both sides, the most dramatic decrease in wound area occurred between days 6 and 18 .

acute to subacute wound healing. Inflammatory cell populations characteristically were first seen to consist predominantly of neutrophils, and were accompanied at this stage by expected hemorrhage, edema, and fibrin (Fig 7). Samples of PSIS were generally readily identifiable as dense, hypereosinophilic linear material within the PSIStreated samples. Tissue sections containing identifiable PSIS material consistently exhibited concentrated populations of viable and degenerate neutrophils surrounding this matrix. The initial cellular infiltrates were followed closely and temporally by macrophages, fibroblasts, neovascularization and, ultimately, fibrous connective tissue over the subsequent sampling intervals.

When quantifying our results, we found a HAIS that was significantly higher in the PSIS-treated wounds on days 2 and 6 when compared with control wounds (Fig 8). The HRS was similar throughout the study period between the PSIS-treated and control wounds (Fig 8). Histologic evaluation of samples of rehydrated PSIS appeared as a dense lamellar collagenous structure with parallel-arrayed fibers. Abundant nuclei were found between the fibers (Fig 9).

\section{Microbiology}

Bacteriologic cultures taken on days $0,4,9$, and 15 yielded 80 samples; 24 were positive (13 PSIS, 11 controls). Pseudomonas sp. and Staphylococcus sp. were the most common isolated species, followed by Clostridium sp., Corynebacterium sp., Escherichia coli, Micrococcus sp., and Streptococcus sp. The number of positive cultures and their score did not differ significantly between treatment and control wounds (Table 1).

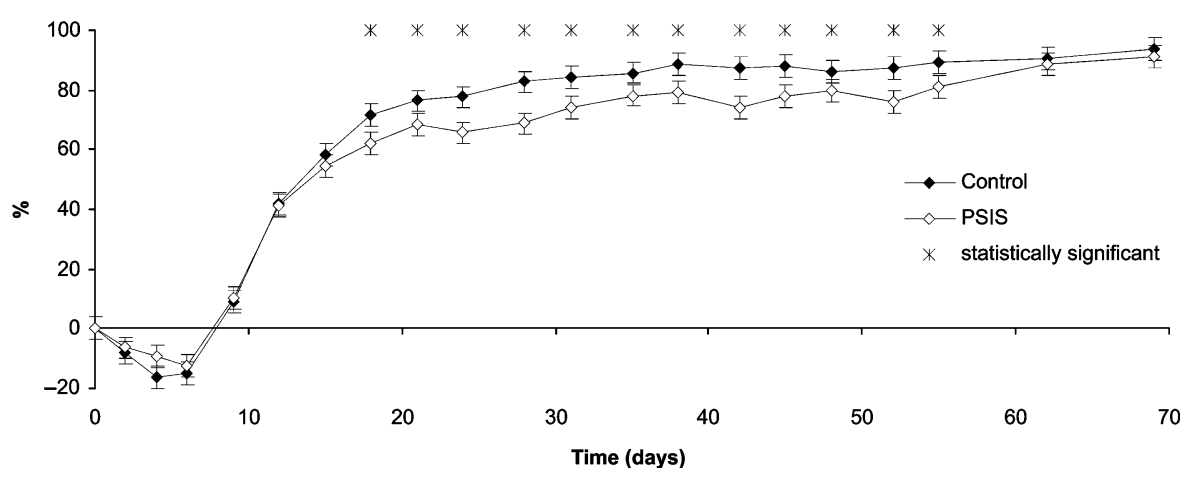

Fig 4. Percent wound contraction compared to initial wound size on day 0 . Note initial wound retraction, followed by significantly greater contraction of control wounds during most of the study. For both sides, the most dramatic contraction occurred between days 6 and 18. 


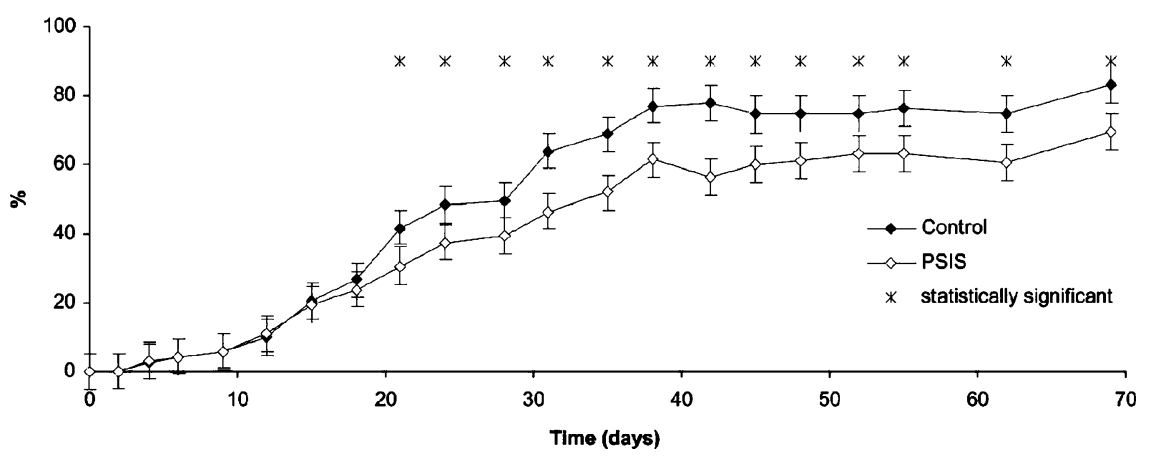

Fig 5. Percent epithelialization compared to the total wound size at each time point. The control wounds had a significantly higher percentage of epithelialization after day 21.

\section{DISCUSSION}

Surgical treatment of large skin wounds can be very challenging and healing by second intention may take several months, as occurred with the large wounds created in this study (average wound size on day 0 was $20.26 \mathrm{~cm}^{2}$ in the control group and $18.88 \mathrm{~cm}^{2}$ in the PSIStreated group), which took more than 2 months to heal.

With microscopic evaluation, we found an accentuated acute inflammatory response that diminished temporally in PSIS-treated wounds. The acute inflammatory
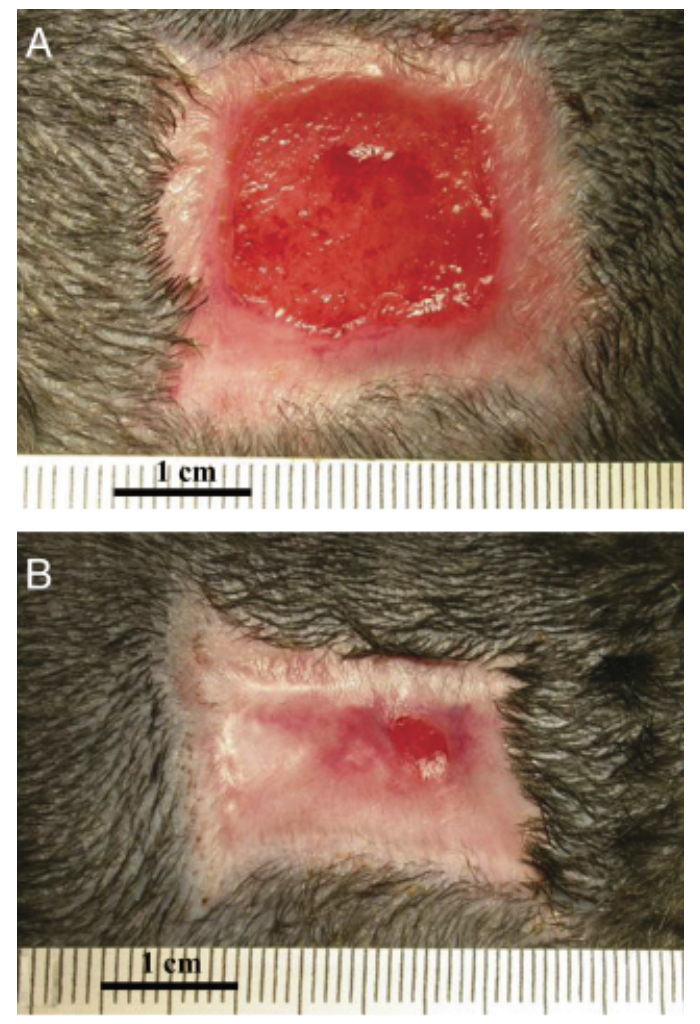

Fig 6. Representative pictures of the porcine small intestinal submucosa-treated side (A) and the control side (B) on the same dog at day 35 . response of control wounds was significantly less marked. The finding of acute inflammation after implantation of PSIS is consistent with other reports. ${ }^{69-72}$ The major component of the PSIS product is collagen protein. Although collagen has maintained a highly conserved
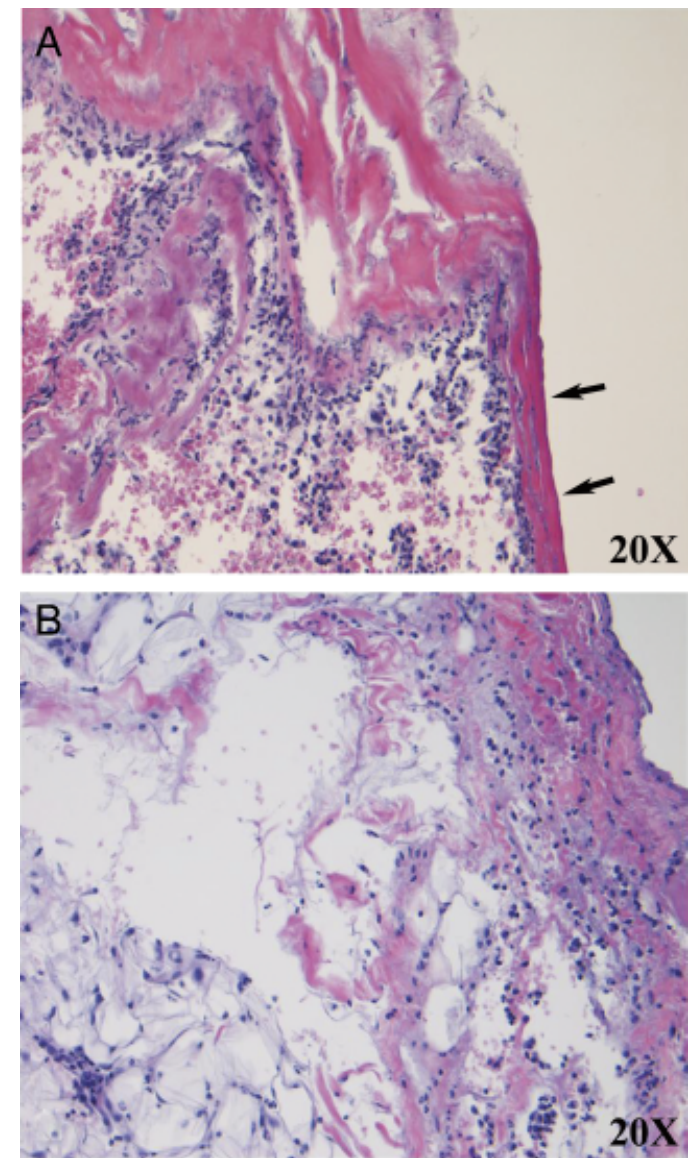

Fig 7. Histologic images of biopsies at day 2. One of the marked differences between wounds treated with porcine small intestinal submucosa (PSIS) (A) and control wounds (B) was the neutrophilic infiltration of the specimens. Note the PSIS implant as dense, eosinophilic, linear material (arrows). 


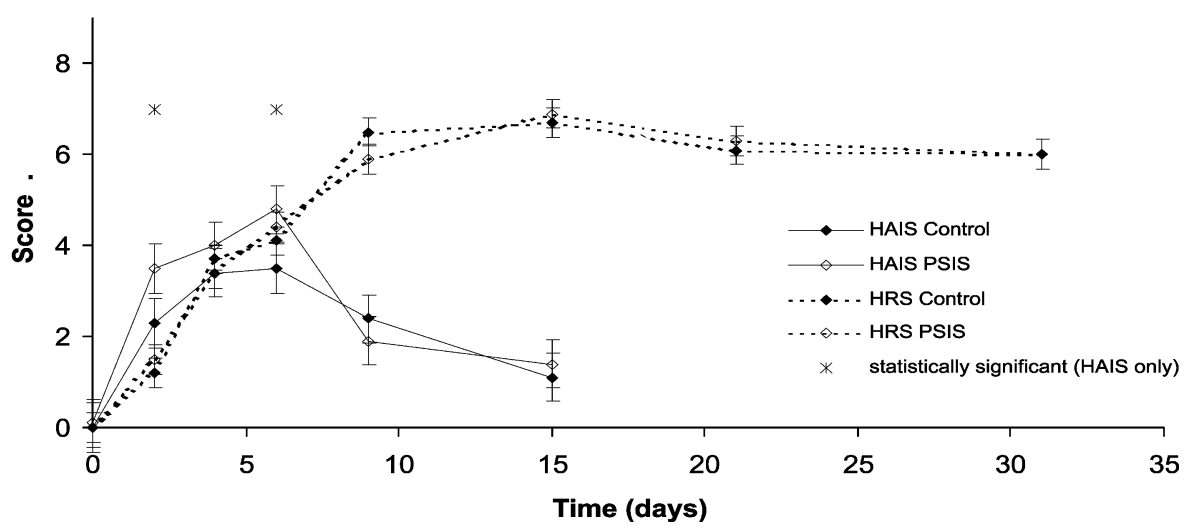

Fig 8. Histologic Acute Inflammation Scores were significantly higher in porcine small intestinal submucosa (PSIS)-treated wounds on days 2 and 6. Histologic Repair Scores were not statistically different between PSIS-treated wounds and the control wounds throughout the collection period.

amino acid sequence during evolution, interspecies structural differences exist throughout the collagen helix (predominantly at both the amino- and carboxy-terminal ends of the chain). ${ }^{73}$ The lack of delayed hypersensitivity response in our study is consistent with many studies. ${ }^{20,29,59,74}$ It has been demonstrated that PSIS induced a predominantly $\mathrm{Th} 2$ immune response when implanted in tissue without the signs of rejection. ${ }^{69,75}$ Histologic evaluation of a sample of rehydrated PSIS material showed a marked nuclear and cellular content. This finding is consistent with a study performed by Zheng et $\mathrm{al}^{72}$, where they evaluated a PSIS product used for tendon repair. They assessed the products histologically, as well as by scanning electron microscopy (SEM); porcine DNA was isolated with the use of nested polymerase chain reaction (PCR). It is possible that the inflammatory reaction caused by the implantation of PSIS is in part because of the presence of porcine nuclear material (Fig 9).

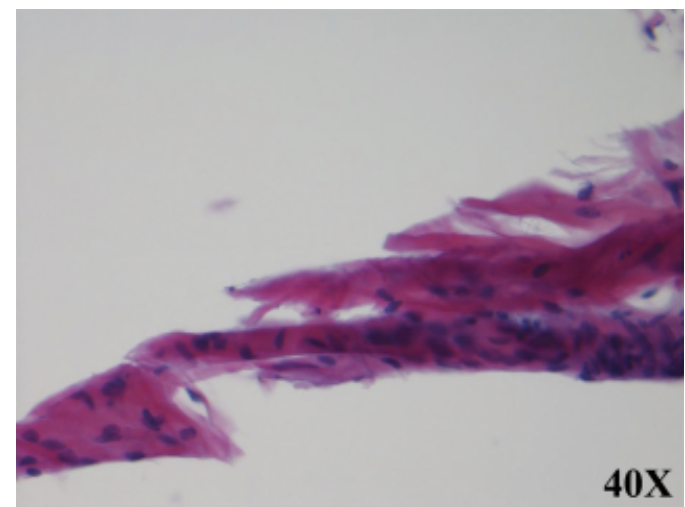

Fig 9. Histologic evaluation of samples of rehydrated porcine small intestinal submucosa appeared as a linear, lamellar, collagenous material, with evidence of fairly evenly interspersed nuclear detail.
Assessment of the HRS, which was a combination of fibroblast proliferation, collagen density, and neovascularization, did not show a difference between PSIStreated wounds and control wounds. This is consistent with findings reported by Winkler et $\mathrm{al}^{29}$ The biopsies for histologic analysis were taken from the cranial wounds, assuming that they would heal identically to the $10 \mathrm{~cm}$ more caudal wounds. This was done (as in previous studies $^{22}$ ) to preserve the integrity of the caudal wounds for accurate planimetric analysis. It is acknowledged, however, that this assumption may be a limitation to our study.

Close similarity between PSIS-treated and control wounds was found in the results of microbial cultures despite earlier reported antimicrobial properties of the PSIS. ${ }^{34}$ This finding is consistent with a recent study by Holtom et al, supporting the apparent lack of any antimicrobial advantage of this dressing. ${ }^{76} \mathrm{We}$ had no obvious clinical signs of infection in any wound, and culture results were mostly polymicrobial with low colony-forming unit counts, typical of wound surface contaminants.

When evaluating wound epithelialization, there was significantly increased percent epithelialization in control wounds compared with PSIS-treated wounds after day 21. This finding diverged from other studies where PSIS-treated wounds had a similar epithelialization rate compared with control wounds. ${ }^{20,28,29}$ The reason for this

Table 1. Results of Aerobic Cultures

\begin{tabular}{|c|c|c|c|c|c|c|c|c|}
\hline & \multicolumn{2}{|c|}{ Day 0} & \multicolumn{2}{|c|}{ Day 4} & \multicolumn{2}{|c|}{ Day 9} & \multicolumn{2}{|c|}{ Day 15} \\
\hline & Control & PSIS & Control & PSIS & Control & PSIS & Control & PSIS \\
\hline No growth & 10 & 9 & 9 & 8 & 5 & 5 & 5 & 4 \\
\hline $0-50 \mathrm{cfu}$ & & 1 & 1 & 2 & 3 & 2 & 3 & 4 \\
\hline $\begin{array}{l}50-100 \mathrm{cfu} \\
>100 \mathrm{cfu}\end{array}$ & & & & & 2 & 3 & 2 & 2 \\
\hline
\end{tabular}

cfu, colony-forming units; PSIS, porcine small intestinal submucosa. 
difference is unknown; however, one possibility may be the fact that wounds in our study were much larger $\left(>16 \mathrm{~cm}^{2}\right)$ compared with the wounds in other studies $\left(2 \mathrm{~cm}^{2}\right.$ with exposed bone in a dog study, ${ }^{29}$ and $4 \mathrm{~cm}^{2}$ full-thickness wounds in another study performed on rats $^{28}$ ).

Another possible reason for delayed epithelialization may be the quality of the granulation tissue. Subjective evaluation of the wound bed showed a smoother granulation tissue surface in the control wounds when compared with PSIS-treated wounds, where the surface had a more uneven appearance (Fig 6). Another possibility could be the way the PSIS sheets were applied into the wound beds. To avoid excessive retraction of the wound edges, we did not undermine, and placed the sheets slightly overlying the edges until day 4 . On day 4 , we trimmed the sheets to the actual wound size. The fact that the PSIS may have slightly overlapped in the wound corners at the suture site, may have covered and impinged upon the mobilizing basal epithelial cells in early healing. If so, PSIS would be more appropriately placed with undermining, or several days after wounding.

Initial mean wound size during the first 9 days was smaller on the PSIS-treated side compared with the controls. All wounds initially retracted and continued to retract until day 4, because of the viscoelastic properties of the skin and cutaneous trunci muscle contraction. PSIStreated wounds did not enlarge as much over this initial period because of the effect of the sutured PSIS sheet holding the wound corners together, thus limiting retraction. After this time, the total wound area of all wounds decreased, with the controls contracting more rapidly than the PSIS-treated wounds. If the implanted PSIS sheet had not been limiting this initial wound retraction, it is likely that this later difference would be even more pronounced. In other words, if the 2 sides started wound contraction with the same wound size, the difference would be even more accentuated. This delay in wound contraction is consistent with findings of a study by Prevel et $\mathrm{al}^{28}$ where full-thickness, 20-mm-diameter wounds in rodents were inflicted. They found an average wound contraction rate of $33 \%$ for the PSIS-treated wounds and $56 \%$ for the control wounds. There are numerous studies that report inhibition of wound contraction after implanting a collagenous ECM into full-thickness wounds. ${ }^{6,77-81}$ This effect is used, and indeed desired, in human wound treatment, where contraction is usually unwanted. In veterinary applications, however, contraction is often a welcome and important attribute of open wound management, unless the wounds are over flexor and extensor aspects of joints, and adjacent to orifices.

We concluded that PSIS is not beneficial in acute, fullthickness wounds in dogs, where contraction is a desired part of the wound repair process. In cases where contraction is contraindicated, the application of PSIS as a dermal substitute to prepare the wound bed for a splitthickness autografts, a cultured epidermal graft or other reconstructive efforts, may be advantageous and should be the focus of further studies.

\section{Acknowledgment}

Funded by the Michigan State University Companion Animal Fund.

\section{REFERENCES}

1. Martina Y, Marcucci KT, Cherqui S, et al: Mice transgenic for a human porcine endogenous retrovirus receptor are susceptible to productive viral infection. J Virol 80:31353146, 2006

2. McIntyre MC, Kannan B, Solano-Aguilar GI, et al: Detection of porcine endogenous retrovirus in cultures of freshly isolated porcine bone marrow cells. Xenotransplantation 10:337-342, 2003

3. Takefman DM, Wong S, Maudru T, et al: Detection and characterization of porcine endogenous retrovirus in porcine plasma and porcine factor VIII. J Virol 75:4551-4557, 2001

4. Wang S, Zinderman C, Wise R, et al: Infections and human tissue transplants: review of FDA MedWatch reports 2001-2004. Cell Tissue Bank 8:211-219, 2007

5. Andreadis ST: Gene-modified tissue-engineered skin: the next generation of skin substitutes. Adv Biochem Eng Biotechnol 103:241-274, 2007

6. Chu CS, McManus AT, Matylevich NP, et al: Integra as a dermal replacement in a meshed composite skin graft in a rat model: a one-step operative procedure. J Trauma 52:122-129, 2002

7. Clark RA, Ghosh K, Tonnesen MG: Tissue engineering for cutaneous wounds. J Invest Dermatol 127:1018-1029, 2007

8. Horch RE, Kopp J, Kneser U, et al: Tissue engineering of cultured skin substitutes. J Cell Mol Med 9:592-608, 2005

9. Metcalfe AD, Ferguson MW: Tissue engineering of replacement skin: the crossroads of biomaterials, wound healing, embryonic development, stem cells and regeneration. J R Soc Interface 4:413-437, 2007

10. Doillon CJ, Whyne CF, Berg RA, et al: Fibroblast-collagen sponge interactions and the spatial deposition of newly synthesized collagen fibers in vitro and in vivo. Scan Electron Microsc 1313-1320, 1984

11. Marks MG, Doillon C, Silver FH: Effects of fibroblasts and basic fibroblast growth factor on facilitation of dermal wound healing by type I collagen matrices. J Biomed Mater Res 25:683-696, 1991

12. Singer AJ, Clark RA: Cutaneous wound healing. N Engl J Med 341:738-746, 1999

13. Eaglstein WH, Falanga V: Tissue engineering and the development of Apligraf, a human skin equivalent. Clin Ther 19:894-905, 1997 
14. Pouliot R, Larouche D, Auger FA, et al: Reconstructed human skin produced in vitro and grafted on athymic mice. Transplantation 73:1751-1757, 2002

15. Shen JT, Falanga V: Innovative therapies in wound healing. J Cutan Med Surg 7:217-224, 2003

16. Wilkins LM, Parenteau NL: Bioengineered skin: manufacturing, safety and quality control, in Falanga V (ed): Cutaneous Wound Healing, Martin Dunitz, London, 2001, pp 399-409

17. Dantzer E, Braye FM: Reconstructive surgery using an artificial dermis (Integra): results with 39 grafts. Br J Plast Surg 54:659-664, 2001

18. Frame JD, Still J, Lakhel-LeCoadou A, et al: Use of dermal regeneration template in contracture release procedures: a multicenter evaluation. Plast Reconstr Surg 113:1330 1338, 2004

19. Jeng JC, Fidler PE, Sokolich JC, et al: Seven years' experience with Integra as a reconstructive tool. J Burn Care Res 28:120-126, 2007

20. Gomez JH, Schumacher J, Lauten SD, et al: Effects of 3 biologic dressings on healing of cutaneous wounds on the limbs of horses. Can J Vet Res 68:49-55, 2004

21. Goodrich LR, Moll HD, Crisman MV, et al: Comparison of equine amnion and a nonadherent wound dressing material for bandaging pinch-grafted wounds in ponies. Am J Vet Res 61:326-329, 2000

22. Ramsey DT, Pope ER, Wagner-Mann C, et al: Effects of three occlusive dressing materials on healing of full-thickness skin wounds in dogs. Am J Vet Res 56:941-949, 1995

23. Lascelles BD, White RA: Combined omental pedicle grafts and thoracodorsal axial pattern flaps for the reconstruction of chronic, nonhealing axillary wounds in cats. Vet Surg 30:380-385, 2001

24. Roa DM, Bright RM, Daniel GB, et al: Microvascular transplantation of a free omental graft to the distal extremity in dogs. Vet Surg 28:456-465, 1999

25. Smith BA, Hosgood G, Hedlund CS: Omental pedicle used to manage a large dorsal wound in a dog. J Small Anim Pract 36:267-270, 1995

26. Swaim SF, Gillette RL, Sartin EA, et al: Effects of a hydrolyzed collagen dressing on the healing of open wounds in dogs. Am J Vet Res 61:1574-1578, 2000

27. Yvorchuk-St Jean K, Gaughan E, St Jean G, et al: Evaluation of a porous bovine collagen membrane bandage for management of wounds in horses. Am J Vet Res 56: 1663-1667, 1995

28. Prevel CD, Eppley BL, Summerlin DJ, et al: Small intestinal submucosa: utilization as a wound dressing in full-thickness rodent wounds. Ann Plast Surg 35:381-388, 1995

29. Winkler JT, Swaim SF, Sartin EA, et al: The effect of a porcinederived small intestinal submucosa product on wounds with exposed bone in dogs. Vet Surg 31:541-551, 2002

30. Hodde JP, Badylak SF, Brightman AO, et al: Glycosaminoglycan content of small intestinal submucosa: a bioscaffold for tissue replacement. Tissue Eng 2:209-217, 1996

31. McPherson TB, Badylak SF: Characterization of fibronectin derived from porcine small intestinal submucosa. Tissue Eng 4:75-83, 1998
32. Voytik-Harbin SL, Brightman AO, Kraine MR, et al: Identification of extractable growth factors from small intestinal submucosa. J Cell Biochem 67:478-491, 1997

33. Hodde JP, Record RD, Liang HA, et al: Vascular endothelial growth factor in porcine-derived extracellular matrix. Endothelium 8:11-24, 2001

34. Sarikaya A, Record R, Wu CC, et al: Antimicrobial activity associated with extracellular matrices. Tissue Eng 8:63-71, 2002

35. Kropp BP, Cheng EY, Lin HK, et al: Reliable and reproducible bladder regeneration using unseeded distal small intestinal submucosa. J Urol 172:1710-1713, 2004

36. Kropp BP, Rippy MK, Badylak SF, et al: Regenerative urinary bladder augmentation using small intestinal submucosa: urodynamic and histopathologic assessment in longterm canine bladder augmentations. J Urol 155:2098-2104, 1996

37. Zhang Y, Frimberger D, Cheng EY, et al: Challenges in a larger bladder replacement with cell-seeded and unseeded small intestinal submucosa grafts in a subtotal cystectomy model. BJU Int 98:1100-1105, 2006

38. Huber JE, Spievack A, Simmons-Byrd A, et al: Extracellular matrix as a scaffold for laryngeal reconstruction. Ann Otol Rhinol Laryngol 112:428-433, 2003

39. Badylak S, Meurling S, Chen M, et al: Resorbable bioscaffold for esophageal repair in a dog model. J Pediatr Surg 35:1097-1103, 2000

40. An G, Walter RJ, Nagy K: Closure of abdominal wall defects using acellular dermal matrix. J Trauma 56:1266-1275, 2004

41. Ansaloni L, Catena F, Gagliardi S, et al: Hernia repair with porcine small-intestinal submucosa. Hernia 11:321-326, 2007

42. Badylak S, Kokini K, Tullius B, et al: Morphologic study of small intestinal submucosa as a body wall repair device. J Surg Res 103:190-202, 2002

43. Badylak S, Kokini K, Tullius B, et al: Strength over time of a resorbable bioscaffold for body wall repair in a dog model. J Surg Res 99:282-287, 2001

44. Gagliardi S, Ansaloni L, Catena F, et al: Hernioplasty with Surgisis(R) Inguinal Hernia Matrix (IHM)trade mark. Surg Technol Int 16:128-133, 2007

45. Soiderer EE, Lantz GC, Kazacos EA, et al: Morphologic study of three collagen materials for body wall repair. J Surg Res 118:161-175, 2004

46. Dalla Vecchia L, Engum S, Kogon B, et al: Evaluation of small intestine submucosa and acellular dermis as diaphragmatic prostheses. J Pediatr Surg 34:167-171, 1999

47. Sandoval JA, Lou D, Engum SA, et al: The whole truth: comparative analysis of diaphragmatic hernia repair using 4-ply vs 8-ply small intestinal submucosa in a growing animal model. J Pediatr Surg 41:518-523, 2006

48. Bejjani GK, Zabramski J: Safety and efficacy of the porcine small intestinal submucosa dural substitute: results of a prospective multicenter study and literature review. J Neurosurg 106:1028-1033, 2007

49. Baltoyannis G, Mitsis M, Nathanael C, et al: Submucosa of canine small intestine as an alternative medium-diameter autogenous arterial graft. Int Angiol 19:280-284, 2000 
50. Sandusky GE, Lantz GC, Badylak SF: Healing comparison of small intestine submucosa and ePTFE grafts in the canine carotid artery. J Surg Res 58:415-420, 1995

51. Shell DH, Croce MA, Cagiannos C, et al: Comparison of small-intestinal submucosa and expanded polytetrafluoroethylene as a vascular conduit in the presence of grampositive contamination. Ann Surg 241:995-1001; discussion 1001-1004, 2005

52. Dejardin LM, Arnoczky SP, Ewers BJ, et al: Tissue-engineered rotator cuff tendon using porcine small intestine submucosa. Histologic and mechanical evaluation in dogs. Am J Sports Med 29:175-184, 2001

53. Badylak SF, Tullius R, Kokini K, et al: The use of xenogeneic small intestinal submucosa as a biomaterial for Achilles tendon repair in a dog model. J Biomed Mater Res 29: 977-985, 1995

54. Gilbert TW, Stewart-Akers AM, Simmons-Byrd A, et al: Degradation and remodeling of small intestinal submucosa in canine Achilles tendon repair. J Bone Jt Surg Am 89:621-630, 2007

55. Androjna C, Spragg RK, Derwin KA: Mechanical conditioning of cell-seeded small intestine submucosa: a potential tissue-engineering strategy for tendon repair. Tissue Eng 13:233-243, 2007

56. Derwin K, Androjna C, Spencer E, et al: Porcine small intestine submucosa as a flexor tendon graft. Clin Orthop Relat Res 245-252, 2004

57. Musahl V, Abramowitch SD, Gilbert TW, et al: The use of porcine small intestinal submucosa to enhance the healing of the medial collateral ligament - a functional tissue engineering study in rabbits. J Orthop Res 22:214-220, 2004

58. Liang R, Woo SL, Takakura Y, et al: Long-term effects of porcine small intestine submucosa on the healing of medial collateral ligament: a functional tissue engineering study. J Orthop Res 24:811-819, 2006

59. Dejardin LM, Arnoczky SP, Clarke RB: Use of small intestinal submucosal implants for regeneration of large fascial defects: an experimental study in dogs. J Biomed Mater Res 46:203-211, 1999

60. Bradley MP, Fadale PD, Hulstyn MJ, et al: Porcine small intestine submucosa for repair of goat meniscal defects. Orthopedics 30:650-656, 2007

61. Cook JL, Fox DB, Malaviya P, et al: Evaluation of small intestinal submucosa grafts for meniscal regeneration in a clinically relevant posterior meniscectomy model in dogs. J Knee Surg 19:159-167, 2006

62. Cook JL, Fox DB, Malaviya P, et al: Long-term outcome for large meniscal defects treated with small intestinal submucosa in a dog model. Am J Sports Med 34:32-42, 2006

63. Welch JA, Montgomery RD, Lenz SD, et al: Evaluation of small-intestinal submucosa implants for repair of meniscal defects in dogs. Am J Vet Res 63:427-431, 2002

64. Moore DC, Pedrozo HA, Crisco JJ III, et al: Preformed grafts of porcine small intestine submucosa (SIS) for bridging segmental bone defects. J Biomed Mater Res A 69: 259-266, 2004

65. Mostow EN, Haraway GD, Dalsing M, et al: Effectiveness of an extracellular matrix graft (OASIS Wound Matrix) in the treatment of chronic leg ulcers: a randomized clinical trial. J Vasc Surg 41:837-843, 2005

66. Romanelli M, Dini V, Bertone M, et al: OASIS wound matrix versus Hyaloskin in the treatment of difficult-to-heal wounds of mixed arterial/venous aetiology. Int Wound J 4:3-7, 2007

67. Niezgoda JA, Van Gils CC, Frykberg RG, et al: Randomized clinical trial comparing OASIS Wound Matrix to Regranex Gel for diabetic ulcers. Adv Skin Wound Care 18:258-266, 2005

68. Kim MS, Hong KD, Shin HW, et al: Preparation of porcine small intestinal submucosa sponge and their application as a wound dressing in full-thickness skin defect of rat. Int $\mathrm{J}$ Biol Macromol 36:54-60, 2005

69. Allman AJ, McPherson TB, Badylak SF, et al: Xenogeneic extracellular matrix grafts elicit a $\mathrm{TH} 2$-restricted immune response. Transplantation 71:1631-1640, 2001

70. Badylak SF: Extracellular matrix scaffolds. Encyclopedia of Biomaterials and Biomedical Engineering 561-567, 2004

71. Brown-Etris M, Cutshall W, Hiles M: A new biomaterial derived from small intestine submucosa and developed into a wound matrix device. Wounds: Compend Clin Res Pract 14:150-166, 2002

72. Zheng MH, Chen J, Kirilak Y, et al: Porcine small intestine submucosa (SIS) is not an acellular collagenous matrix and contains porcine DNA: possible implications in human implantation. J Biomed Mater Res B Appl Biomater 73:61-67, 2005

73. Lindsley H, Mannik M, Bornstein P: The distribution of antigenic determinants in rat skin collagen. J Exp Med 133:1309-1324, 1971

74. Kropp BP, Eppley BL, Prevel CD, et al: Experimental assessment of small intestinal submucosa as a bladder wall substitute. Urology 46:396-400, 1995

75. Ansaloni L, Cambrini $\mathrm{P}$, Catena F, et al: Immune response to small intestinal submucosa (surgisis) implant in humans: preliminary observations. J Invest Surg 20:237-241, 2007

76. Holtom PD, Shinar Z, Benna J, et al: Porcine small intestine submucosa does not show antimicrobial properties. Clin Orthop Relat Res 18-21, 2004

77. Inoue M, Ono I, Tateshita T, et al: Effect of a collagen matrix containing epidermal growth factor on wound contraction. Wound Repair Regen 6:213-222, 1998

78. MacLeod TM, Sarathchandra P, Williams G, et al: Evaluation of a porcine origin acellular dermal matrix and small intestinal submucosa as dermal replacements in preventing secondary skin graft contraction. Burns 30: 431-437, 2004

79. Ono I, Tateshita T, Inoue M: Effects of a collagen matrix containing basic fibroblast growth factor on wound contraction. J Biomed Mater Res 48:621-630, 1999

80. Srivastava A, DeSagun EZ, Jennings LJ, et al: Use of porcine acellular dermal matrix as a dermal substitute in rats. Ann Surg 233:400-408, 2001

81. Walden JL, Garcia H, Hawkins H, et al: Both dermal matrix and epidermis contribute to an inhibition of wound contraction. Ann Plast Surg 45:162-166, 2000 